\section{P509 USE OF INTERNET/MOBILE DATING APPS TO FIND SEX PARTNERS AMONG A NATIONALLY REPRESENTATIVE SAMPLE OF MEN WHO HAVE SEX WITH MEN}

${ }^{1}$ Rachel Kachur*, ${ }^{2}$ Casey Copen, ${ }^{3}$ Frank Strona, ${ }^{4}$ Bruce Furness, ${ }^{5}$ Kyle Bernstein, ${ }^{2}$ Matthew Hogben. ${ }^{1}$ Centers for Disease Control and Prevention, Division of STD Prevention, Brookhaven, USA; ${ }^{2}$ Centers for Disease Control and Prevention, Division of STD Prevention, Atlanta, USA; ${ }^{3}$ Centers for Disease Control and Prevention, Division of STD Prevention, San Francisco, USA; ${ }^{4}$ Centers for Disease Control and Prevention, Division of STD Prevention, Washington DC, USA; ${ }^{5}$ Centers for Disease Control and Prevention, Atlanta, USA

10.1136/sextrans-2019-sti.589

Background Associations between online sex seeking and increased risk for STDs and HIV among men who have sex with men (MSM) typically rely on convenience samples. We examined the prevalence of internet and mobile app use for finding sex partners among a nationally representative sample of MSM.

Methods We analyzed 2011-2017 data from the National Survey of Family Growth, a nationally representative sample of the civilian, non-institutionalized US population (15-44 years). The analytic sample was comprised of males who reported one or more same-sex partners in the past year. We also assessed associations between online sex-seeking and STD risk, sexual health service use, and condom use.

Results Of 13,320 male respondents, 442 (3.0\%) reported sex with a man in the past year, of whom 227 (53.7\%) had met a partner online. Between MSM who met partners online and those who did not, we found no differences by age, education, race/ethnicity or socioeconomic status. MSM with online partners were more likely to identify as gay $(69.5 \%$ vs $49.4 \%, \mathrm{p}<0.02)$. They also reported more sex partners overall $(M=3.1$ versus $1.6, \mathrm{p}<0.0001)$, and more insertive $(33.1 \%$ versus $15.4 \%, \mathrm{p}<0.006)$ and receptive $(46.3 \%$ versus $8.5 \%, \mathrm{p}<0.0001)$ anal sex partners, in the past year. They were also more likely to receive sexual risk assessments $(56.0 \%$ versus $40.4 \%, \mathrm{p}<0.02)$, STD testing $(57.4 \%$ versus $35.3 \%, \mathrm{p}=0.0002)$ and STD treatment $(17.8 \%$ versus $8.7 \%$, $\mathrm{p}<0.02)$ in the past year. We found no differences in condom use.

Conclusion MSM who report using online sources to find sex partners are more likely than other MSM to report behaviors that increase risk for STD/HIV, but are also more likely to engage in behaviors that may mitigate risk, such as STD testing.

Disclosure No significant relationships.

\section{P510 CHEMSEX AMONG MEN WHO HAVE SEX WITH MEN IN A MIXED URBAN-NON-URBAN AREA AND ASSOCIATIONS WITH SEXUALLY TRANSMITTED INFECTIONS}

Ymke Evers, Geneviève Van Liere, Christian Hoebe*, Nicole Dukers-Muijrers. Public Health Service South Limburg, Maastricht University Medical Center (MUMC), Sexual Health, Infectious Diseases and Environmental Health, Medical Microbiology, Care and Public Health Research Institute (CAPHRI), Heerlen, Netherlands

10.1136/sextrans-2019-sti.590

Background The intentional use of drugs to have sex - chemsex - among men who have sex with men might contribute to the high STI prevalence in this group. Limited data is available on chemsex outside major cities in Europe. The current study investigated the use of a wide variety of drugs during sex in a mixed urban-non-urban area in the Netherlands and their associations with STI.

Methods At two Dutch STI clinics, 350 MSM were recruited and 250 MSM completed an online questionnaire in 2018. Questionnaire data were linked to clients' most recent STI laboratory test results. Chemsex was defined as using cocaine, crystal meth, designer drugs, GHB/GBL, ketamine, speed, or XTC/MDMA during sex in the preceding six months. The use of other drugs was also assessed. Determinants (any drug use, chemsex, specific drugs, number of drugs, combining, and frequency) potentially associated with STI were assessed using multivariable logistic regression analyses adjusting for sociodemographic characteristics and sexual history.

Results Chemsex was reported by 35\% (95\%CI: 29-41) of the 250 participants. XTC/MDMA $(27 \% ; 68 / 250)$ and GHB/ GBL $(26 \% ; 64 / 250)$ were the most used drugs. STI positivity was 33\% (29/87) in MSM engaging in chemsex and 12\% (12/ $163)$ in MSM not engaging in chemsex $(p<0.001)$. Half of MSM engaging in chemsex $(45 / 87)$ used three of more different chemsex drugs; STI positivity in this group was 44\% (20/ 45). The only factor independently associated with STI was the use of three or more chemsex drugs (aOR: 4.13, 95\% CI:1.77-9.62).

Conclusion This study shows that chemsex is prevalent among MSM visiting the STI clinic outside major cities in the Netherlands, suggesting that health services in both urban and nonurban areas should be aware of and informed on chemsex. MSM who used multiple drugs are at particular risk for STI, indicating a special need for STI prevention and care in this group.

Disclosure No significant relationships.

\section{P511 SURVEILLANCE OF LYMPHOGRANULOMA VENEREUM AMONG MEN WHO HAVE SEX WITH MEN ATTENDING STI CLINICS IN ALBERTA, CANADA, 2018}

${ }^{1}$ Jennifer Gratrix, ${ }^{1}$ John Niruban, ${ }^{2}$ Alberto Severini, ${ }^{2}$ Jennifer Beirnes, ${ }^{3}$ Prenilla Naidu, ${ }^{4}$ Angel Chu, ${ }^{5}$ Ameeta Singh, ${ }^{1}$ Petra Smyczek* ${ }^{1}$ Alberta Health Services, Centralized STI Services, Edmonton, Canada; ${ }^{2}$ Public Health Agency of Canada, National Microbiology Laboratory, Winnipeg, Canada; ${ }^{3}$ Provincial Laboratory for Public Health, Edmonton, Canada; ${ }^{4}$ Alberta Health Services, Calgary STI Clinic, Calgary, Canada; ${ }^{5}$ University of Alberta, Internal Medicine, Edmonton, Canada

10.1136/sextrans-2019-sti.591

Background Lymphogranuloma venereum (LGV) is a sexually transmitted infection (STI) caused by Chlamydia trachomatis (CT) biovars L1-3, which has been increasingly reported among men who have sex with men (MSM). Our study aimed to establish a surveillance system among MSM attending STI clinics in Alberta, Canada to determine prevalence and characteristics of cases.

Methods CT NAAT (Genprobe Aptima COMBO $2^{\circledR}$ Assay) positive specimens from all anatomical sites among MSM attending three STI clinics between May to November 2018 had real-time PCR and DNA sequencing for LGV. Demographic, clinical, and sexual behaviours of cases were extracted from the provincial reporting database. Clinic-stratified analysis was performed to identify differences in sample characteristics using Chi-square or Fisher's exact test.

Results A total of 340 specimens from 299 CT cases were tested for LGV. CT cases were reported from Calgary $(52.8 \%$; $\mathrm{n}=158)$, Edmonton $(46.2 \% ; \mathrm{n}=138)$, and Fort McMurray $(1.0 \% ; \mathrm{n}=3)$. There were no significant differences in 